\title{
The Effect of Using Digital Storytelling on Developing Active Listening and Creative Thinking Skills
}

\author{
Ahmad A.S. Tabieh* \\ Middle East University, \\ JORDAN
}

\author{
Mohamed M. Al-Hileh \\ Middle East University, \\ JORDAN
}

\author{
Haya M. J. Abu Afifa \\ Scientific Research School, \\ UNITED ARAB EMIRATES
}

\author{
Hiba Yacoub Abuzagha \\ Middle East University, \\ JORDAN
}

Received: July 8, 2020 • Revised: October 4, 2020 • Accepted: November 10, 2020

\begin{abstract}
This study aims at investigating the impact of implementing digital storytelling as a method to be utilized to help pupils acquire active listening skills and creative thinking skills, including fluency, flexibility, and originality, in the Arabic language classes of the primary third grade. The sample consists of (200) pupils in a mixed-gender type and divides into two equal groups; one is the experimental group, and the other is the control one. Both groups expose to two posttests, the first test is a post active listening test and the second is a creative thinking test; the validity and reliability of these tests have assured. The results showed significant differences in $(\mathrm{p} \leq 0.05)$ between means scores of the control and experimental groups students in the posttest of active listening skills in favor of the students who studied through storytelling. The results also showed that the storytelling strategy affected the experimental group students' acquisition of one skill of the three creative thinking skills, which is fluency.
\end{abstract}

Keywords: Digital storytelling strategy, active listening, creative thinking, Arabic language.

To cite this article: Tabieh, A. A. S., Al-Hileh, M. M., Abu Afifa, H. M. J., \& Abuzagha, H. Y. (2021). The effect of using digital storytelling on developing active listening and creative thinking skills. European Journal of Educational Research, 10(1), 13-21. https://doi.org/10.12973/eu-jer.10.1.13

\section{Introduction}

Language considers as a means of expression and communication among individuals and societies. It has great importance in empowering children to form their world with all its dimensions. Therefore, it means for developing children's sensory perceptions, mental abilities, and social skills. Through these skills and abilities, they can communicate within the school and outside world. Any language consists of four primary skills: reading, writing, listening, and speaking. Listening considers an essential skill in language acquisition and learning. It is a means of oral communication among individuals by using different ways. Listening is the first condition for developing the language and enriching the linguistic bank of the child. Therefore, it is vital to seek implementation of new strategies in helping students enhance this particular skill in addition to the active listening skill, which involves listening with all the senses and interacting with the speaker by showing verbal and non-verbal responses that indicate comprehension (Cunsolo Willox et al., 2012; Ellison \& Wang, 2018).

In a language that distinguished by being a phonetic language in which letters correspond to sounds like the Arabic language, listening plays a significant role in language acquisition; therefore, Arabic teachers are in continuous seek for new strategies to develop this skill.

One of the new strategies' teachers can utilize in helping pupils enhance their listening skills is digital storytelling. Digital storytelling has come to light over the past years as a useful instruction and teaching style. It has a greatly positive impact on motivating the learner to participate in the teaching-learning process seriously, which leads to indepth content, the novelty in the style of presentation, allows the learners to express the knowledge they knew already, and integrate it into the content, in more serious, interactive and committed way (Hamilton et al., 2019; Wu \& Chen, 2020).

Digital storytelling defines as a collection of the author's stories that work with an electronic mediator (CD) by adding some techniques related to sound, image, color, animated images, and musical effects. These tales depend upon events, narration and storytelling, characters and drama lines, and the climax, as well as the setting and the moral. All the previous elements make language acquisition an entertaining, educational experience (Kervin \& Mantei, 2017).

\footnotetext{
* Corresponding author:

Ahmad A.S. Tabieh, Middle East University, Faculty of Educational Sciences, Jordan. $₫$ atabieh@meu.edu.jo
} 
The story, in general, and digital storytelling, characteristically, can achieve many educational benefits and outcomes. Among the academic services in the educational sector reported by Akard et al. (2015) represent a model that integrates technology successfully in the teaching-learning process. This technology-based model also develops the skills of creative thinking, especially fluency and flexibility, and develops critical thinking and constructive criticism skills. Moreover, it helps children to cast aside introversion and shyness. It also improves and develops communication, whether it is through audio, visual, or written forms. It aims to raise the level of electronic, oral, expression, and listening competencies and support self-representation through participation and expressing an opinion or a thought.

$\mathrm{Ng}$ and Nicholas (2015)classified digital storytelling into ethics and ideals, social, historical, adventures, comics, and avatar stories.

\section{Study definitions}

The following terms define conceptually and operationally.

Creative thinking Skills: The set of skills that enable the person to come up with unique ideas and review them uniquely. These skills require constant exercise to stay alert and focused and apply various thinking techniques to reach the mindset through which a person goes to new and innovative ideas (Kardoyo et al., 2020; Toheri et al., 2020).

The operational definition of creative thinking is the total score obtained by primary third-grade pupils, from the study sample, in creative thinking skills (fluency, flexibility, and originality) on the creative thinking test that prepares for this study.

Digital storytelling The art of storytelling, integrated with multimedia of voice, image, video, and technical software, to tell anecdotes or narrate events or inform the learners about a subject (Robin, 2008).

The operational definition of the digital storytelling is a collection of purposeful stories, with story elements of events, characters, time and place presented by the computer through laserdiscs, or CD - ROMs, or through the internet. Three stories were presented in this study.

Active listening skills: An active constructive process that includes activating the listener for his previous knowledge and aims to help the listener understand the audible test (Doyle, 2019; Finch \& Crunkilton, 1998).

The operational definition is a dynamic behavior that requires primary third-grade pupils to have some skills such as the interaction with the audio material, communication, assuming responsibility, attention to the message and understanding it, the formation of meaning, and the audio translation of the text into words.

\section{Literature Review}

\section{Active Listening}

Weger et al. (2014) define listening skills as an active, constructive process that includes activating the listener to his previously obtained knowledge that aims to help him understand the listened text. There were some distinct characteristics of listening skills, summarized by Hutchins et al. (2013), that listening is one of the language phonoreception skills, through which voices and language symbols are transferred through the auditory nerve to the hearing center in the brain. So, a new process is based on analyzing and explaining the message will start. It is a lively, active reception process in which a set of higher thinking skills is employed, such as understanding, analyzing, synthesis, interpretation, judgments, and criticizing them by applying constructive criticism.

It can be said that active listening is essential in the communication process. It plays a crucial role in the teachinglearning process. The more the listener is characterized by active listening, the more he/she will be a positive listener who can interact with the audio material, understands what he listens to, and concentrates on it (Kawamichi et al., 2015).

The importance of active listening emerges in the teaching-learning process since it is essential and necessary in any language acquisition; it provides the basis of other speech aspects and contributes to improving cognitive development (Kohpeima Jahromi et al., 2016).

Listening as a skill is not restricted only to receiving sounds and perceiving meanings, but it is also a mental effort that involves inferring, disproving analysis, and interpreting of information. Therefore, listening is an integrated performance that requires the listener to use his/her sight and hearing senses and the power of the mind in following up with the speaker's speech to understand, comprehend, and determine ideas (Patrick, 2019).

One of the previous studies related to active listening was conducted by Kourmousi et al. (2017), which examined the Active Listening Attitude Scale (ALAS) validity and reliability in a sample of 3955 Greek educators. The sample was randomly split, and exploratory factor analysis (EFA) was conducted in the even subsample to evaluate the scale's construct validity. Teachers, consultants, and local social researchers participated in the study. Topics related to social relations were selected. The findings showed a significant relationship between social topics and active listening, 
concern, and cooperation. The findings also showed the importance of recreation, and an observed improvement regarding listening and social skills.

Dehham et al. (2018) conducted a study to improve listening comprehension by using interactive listening activities depending on the teacher's reciprocal teaching strategies.

The researcher followed the experimental design into which a random sample from the fifth elementary stage at AlThawra preparatory school for girls has been chosen. The researcher divided the sample into two groups, experimental and control, each comprising 30 students, and pre-tested the two groups. Then, she applied the joint listening activities on the experimental group while applying the prescribed way with the control group. She then taught the two groups to eliminate the teacher variable. After completing the second semester, the researcher posttest the two groups to measure the difference between the two groups' progress.

The results obtained from the statistical data of the study conducted by Dehham et al. (2018) proved that there was an improvement in the students' listening comprehension skill for the experimental group students, which means that reciprocal listening activities affect students' listening comprehension.

\section{Digital Storytelling}

Digital storytelling has emerged lately as a useful tool that keeps both students and teachers positively engaged in the teaching-learning process. However, little attention and focus have been given to a theoretical framework to be implemented to improve technology's effectiveness as a necessary tool in the classroom environment. A discussion of the history of storytelling and how to utilize it in the educational field and particularly in the Arabic language acquisition is presented in this article. The theoretical framework, the technological pedagogical content knowledge (TPCK), is described along with a discussion of how this model should be implemented and applied successfully with digital storytelling. (Duman \& Göcen, 2015)

Robin (2008) has conducted a study that aimed to investigate teachers' usage of digital storytelling in classrooms and detect the effect of this usage on students. This study's findings present that digital storytelling is a good, useful tool in combining instructional messages and learning activities to create a more engaging, exciting, and enjoyable learning environment. It is a successful strategy for creating a positive and constructive learning environment that integrates modern teaching and learning principles. Thus, this strategy focuses on enhancing the student's engagement level and paves the way to a more successful educational experience and journey for learners.

Digital storytelling effectively brings children's attention in listening to topics, increases their concentration in events, and makes them feel engaged in an enjoyable and entertaining environment. Through listening and watching, digital storytelling enables them to imagine and then to identify the similarities between characters in reality to the ones of the story (Simsek, 2020). It also contributes to enhancing the ability to analyze and criticize better than hearing the story in a traditional style, as well as; children learn through digital storytelling how to arrange thoughts chronologically, form meaningful sentences, and tell stories after watching and hearing the story (Lisenbee \& Ford, 2018) .

Since no Arabic or foreign study investigated the digital storytelling variable, active listening skills, and creative thinking skills together, within the limits of the researchers' knowledge, the present study could be considered the first study in Jordan. It came as a response to investigating the effectiveness of digital storytelling in developing active listening and the pupils' creative thinking skills.

Based on the findings of the studies about the roles of modern technology in the teaching-learning process, and utilizing them in an integrated method with the curriculum, and according to the different results regarding the effects of using technology and employing them by students and teachers on the learning process outputs in general. Due to the importance of improving the level of mastering Arabic language skills (Fleith, 2020), which is considered as a key for other sciences from one aspect, and employing modern technology in education from another aspect, this encouraged the researchers to study the role of the educational digital storytelling and examine its effect on the development of active listening and creative thinking skills for primary third-grade pupils (Kardoyo et al., 2020). Mastering listening skills in the early educational stages represents a problem with many dimensions that will encounter students in higher educational stages, such as following up lectures and writing the most critical information, mainly note-taking skills. 


\section{Methodology}

\section{Research Goal}

This study came to investigate the effect of digital storytelling on the development of active listening and creative thinking skills for primary third-grade pupils, as well as; there was a sense of inadequacy in the reality of education, which is based primarily on memorizing and doesn't develop creativity and innovation among pupils, the present study seeks to answer the following central question:

What is the effect of teaching the Arabic language by using digital storytelling for third primary pupils to develop active listening and creative thinking skills?

From this question, the following two null hypotheses emerged:

- The first null hypothesis states that: There were no significant differences at $(\alpha=0.05)$ between the means of primary third-grade pupils in the post active listening skills test in the Arabic language attributed to the employment of teaching strategy by digital storytelling and traditional method.

- The second null hypothesis states that: There were no significant differences in $(\alpha=0.05)$ between the means of primary third-grade pupils in the post creative thinking skills test in the Arabic language attributed to the digital storytelling strategy and ordinary method.

\section{Sample and Data Collection}

Pupils from two divisions of primary third grade were chosen purposively. One of the two divisions was selected randomly to be the experimental group. The number of pupils in this group was (100) male and female pupils, while the second division was the control group whose pupils were (100) male and female pupils in Jordan.

The Experimental Group studied Three Stories by collecting purposeful stories, with story elements of events, characters, time, and place presented by the computer through laserdiscs, or CD - ROMs, or through the internet. The control group studied the same stories traditionally by reading.

Three instruments were applied in the present study. They are (a) the post active listening skills test, (b) the creative learning posttest, and (c) teaching plans. The two tests' validity and reliability were assured by applying these tests on a pilot study consisting of 30 students out of the study sample. The content validity of the teaching plans was assured too.

The instrument was applied to a pilot sample of 30 students, not including the experimental sample. The two instruments featured a correlation coefficient at $(0.78$ and 0.70$)$, which demonstrated a level of validity that allows the instruments' application. The instrument's reliability was verified using the Half Split method yielding a Cronbach's alpha Coefficient of (0.86 and 0.90), which showed good reliability. Table (1) shows the correlation coefficient and Cronbach's alpha according to creative thinking skills.

Table 1. Correlation coefficient and Cronbach's Alpha of creative thinking skills

\begin{tabular}{ccccc}
\hline \multirow{2}{*}{ Dimensions } & \multirow{2}{*}{ Sub dimensions } & \multicolumn{2}{c}{ Validity } & Reliability \\
\cline { 2 - 5 } & & Pearson Correlation & Sig & Cronbach's Alpha \\
\hline \multicolumn{2}{c}{ Active Listening } & 0.70 & $0.000^{*}$ & 0.90 \\
& fluency & 0.82 & $0.000^{*}$ & 0.91 \\
Creative Thinking Skill & Flexibility & 0.77 & $0.000^{*}$ & 0.81 \\
& Originality & 0.74 & $0.000^{*}$ & 0.85 \\
& Overall & 0.78 & $0.000^{*}$ & 0.86 \\
\hline
\end{tabular}

\section{Analyzing of Data}

To investigate the effect of teaching the Arabic language by using digital storytelling for basic third-grade pupils (Independent Variables) in developing active listening and creative thinking skills (two Dependent Variables) in Jordan.

- The Normality distribution was examined by the Shapiro-Wilk test. The results showed that the sampled population is normally distributed with $\mathrm{D}(100)=0.083, \mathrm{P}=200$

- Means and standard deviations of the two groups' performance were calculated to find out any differences between these groups

- Adjusted means and standard deviations were calculated to neutralize the effect of any confounding variables

- LSD test for post comparisons was calculated to find the effect of each teaching method after neutralizing the differences that resulted from the interaction between these teaching methods, i.e., the confounding variables. 


\section{Results}

\section{Results Related to the First Null hypothesis}

The findings related to the first null hypothesis states, "There were no significant differences in $(\alpha \leq 0.05)$ between the means of basic third-grade pupils in the post active listening skills test in the Arabic language attributed to the employment of teaching strategy by digital storytelling and traditional method.

To test this hypothesis and determine whether the differences between the means are significant in ( $\alpha \leq 0.05$ ), ANCOVA was used. Table 2 shows the findings:

Table 2. ANCOVA for basic third-grade pupils on the post active listening skills test, between the experimental and control groups, according to the teaching method used in instruction

\begin{tabular}{lcccccc}
\hline Source of Variation & $\begin{array}{c}\text { Sum of } \\
\text { Squares }\end{array}$ & $\begin{array}{c}\text { Degrees of } \\
\text { Freedom }\end{array}$ & $\begin{array}{c}\text { Mean } \\
\text { Squares }\end{array}$ & F-Value & $\begin{array}{c}\text { Level of } \\
\text { Sig. }\end{array}$ & $\begin{array}{c}\text { Partial Eta } \\
\text { Squared }\end{array}$ \\
\hline Post achievement & 483.225 & 1 & 483.225 & 19.65 & 0.000 & 0.84 \\
Method used & 376.453 & 1 & 376.453 & 15.308 & 0.000 & 0.77 \\
Error & 811.537 & 33 & & & & \\
\hline The adjusted total & 1696 & 35 & & & \\
\hline
\end{tabular}

Table 2 shows that the "F" value of the post active listening skills test, according to the teaching method used in the instruction, was (15.308) at (0.000) level of significance. This value means that there were significant differences between the means of basic third grade third-grade pupils on post active listening skills test in the Arabic language, according to the method used. This result means that the null hypothesis is rejected. The table also shows that $84 \%$ of the variance is associated with post achievement; $77 \%$ of the variance is associated with the teaching method. This result means that post achievement is the most important main effect.

The adjusted means of the two group's performance on the post active listening skills test were extracted to determine the return of differences. Table 3 shows the findings.

Table 3. Adjusted means, standard errors of the performance of the study subjects on the post active listening skills test according to the method used in instruction

\begin{tabular}{lccc}
\hline The method used in instruction & Number of pupils & Adjusted Mean & Standard Error \\
\hline Ordinary Method & 100 & 80.58 & 1.20 \\
Digital Storytelling & 100 & 87.06 & 1.14 \\
\hline
\end{tabular}

Table 3 shows that the adjusted mean of the post active listening skills test for the experimental group individuals who studied using digital storytelling was higher than the adjusted mean for the control group individuals who studied by using the ordinary method. The experimental group's adjusted mean was (87.06), while the mean for the control group was (80.58).

\section{Results Related to the Second Null hypothesis.}

The findings related to the second null hypothesis that states, "There were no significant differences in ( $\alpha \leq 0.05$ ) between the means of basic third-grade pupils in the post creative thinking skills test in the Arabic language, attributed to the digital storytelling strategy and ordinary method.

To test this hypothesis and determine whether the differences between the means are significant ( $\alpha \leq 0.05)$, MANOVA was used. Table (4) shows the findings. 
Table 4. Multivariate analysis of variance (MANOVA) for the study subject's performance on the most creative thinking skills test according to the method used in instruction

\begin{tabular}{|c|c|c|c|c|c|c|c|}
\hline Source of Variation & $\begin{array}{l}\text { Creative thinking } \\
\text { skills }\end{array}$ & Sum of Squares & $\begin{array}{l}\text { Degrees } \\
\quad \text { of } \\
\text { freedom }\end{array}$ & $\begin{array}{l}\text { Mean of } \\
\text { squares }\end{array}$ & F-value & $\begin{array}{l}\text { Level of } \\
\text { sig. }\end{array}$ & $\begin{array}{c}\text { Partial Eta } \\
\text { Squared }\end{array}$ \\
\hline \multirow{4}{*}{$\begin{array}{l}\text { The method used in } \\
\text { instruction }\end{array}$} & fluency & 2.008 & 1 & 2.008 & 0.440 & 0.053 & 0.00 \\
\hline & Flexibility & 4.022 & 1 & 4.022 & 0.112 & 0.740 & 0.00 \\
\hline & Originality & 194.348 & 1 & 194.348 & 3.821 & 0.059 & 0.71 \\
\hline & Total score & 301.487 & 1 & 301.487 & 0.887 & 0.353 & \\
\hline \multirow{4}{*}{ Error } & fluency & 1499.928 & 33 & 45.452 & & & \\
\hline & Originality & 1180.802 & 33 & 35.782 & & & \\
\hline & Originality & 1678.648 & 33 & 50.868 & & & \\
\hline & Total score & 11218.5 & 33 & 339.955 & & & \\
\hline \multirow{4}{*}{ Adjusted total score } & fluency & 1584.972 & 35 & & & & \\
\hline & Flexibility & 1184.972 & 35 & & & & \\
\hline & Originality & 1922 & 35 & & & & \\
\hline & Total score & 11526.22 & 35 & & & & \\
\hline
\end{tabular}

Table 4 shows that the "F" value for fluency dimension, according to the method used, was (0.044) in (0.035 Sig), which means that there were significant differences in $(\alpha \leq 0.05)$ between the means of the two group's performance, on fluency dimension attributed to the method used in teaching Arabic language to basic third-grade pupils. The adjusted means of the experimental and control group are $(82.6,79.1)$, respectively. The table also shows that originality is the most important main effect.

Concerning the flexibility dimension, the "F" value was (0.112) in (0.740 Sig), according to the method used in teaching, which means that there were no significant differences in $(\alpha \leq 0.05)$ between the means of the two group's performance on flexibility dimension attributed to the method used in teaching Arabic language to basic third-grade pupils.

The "F" value of originality dimension, according to the method used in teaching was (3.821) in (0.059 Sig), which means that there were no significant differences in $(\alpha \leq 0.05)$ attributed to the method used in teaching Arabic language to basic third-grade pupils.

Table 4 also shows that the " $F$ " value of the total score of the creative thinking test according to the method used in teaching was (0.887) in ( $0.353 \mathrm{Sig})$, which means that there were no significant differences in ( $\alpha \leq 0.05)$ between the means of the two group's performance attributed to the method used in teaching.

According to these findings, the second null hypothesis was accepted concerning the skills (flexibility, originality, and Overall) and reject regarding fluency.

\section{Conclusion}

- Teaching using digital storytelling affects active listening skills development for basic third-grade pupils in Arabic compared with ordinary methods.

- Teaching using digital storytelling does not affect creative thinking development in levels (flexibility and originality) for basic third-grade pupils in the Arabic language compared with the ordinary method.

- Teaching using digital storytelling affects creative thinking development in fluency Level, for primary third-grade pupils in the Arabic language compared with the ordinary method.

\section{Discussion}

\section{Effectiveness of Digital Storytelling Strategy for Teaching the Arabic Language on active listening skills?}

This result may be attributed to instruction's effectiveness by using a digital storytelling strategy, which contributes to simplifying teaching and language acquisition, continuity of pupils' enthusiasm to learn, concentrating their attention, and increasing motivation for listening. Integrating information technology in the educational process helps in attracting a pupil's attention. It stimulates his/her motivation to learn, as well as increases his interaction with his/her peers and makes him/her not only interested but also curious about the next learning step (Cunsolo Willox et al., 2012; McLellan, 2007; Price et al., 2015; Tan et al., 2014). Digital storytelling is considered as a typical tool for that. It declaims the multiple intelligences of leaders. It is considered as an incubator of diversity in learning styles (Doyle, 2019).

This result may be attributed to the pupil's positive participation in the events and characters of the story. He/she listens to the soundtrack, views images and movements to become more motivated to listen. This may appear to achieve satisfactory teaching-learning outcomes (Hamilton et al., 2019; Nam, 2017). 
Applying the digital storytelling technique is the most effective and successful method to apply to enhance the pupils' acquisition of the language (Duman \& Göcen, 2015). It is also viewed as the most appropriate way to bring the literary genres into a vivid mental image that contributes to building and enriching the vocabulary bank of pupils, stimulating their senses, including hearing and the sense of sight. It introduces the receptive skill in a modern model that complies with the modern era requirements that are distinguished by the technological evolution (Copeland \& de Moor, 2018; Nam, 2017; Wechsler et al., 2018).

Listening is the receptive skill that any person depends on to acquire the language. it provides the learner with more than just words or sounds but the structure, intonation, and recalling information to interpret them (Doyle, 2019). Therefore, empowering the approach of teaching listening through utilizing the digital storytelling method can have a positive contribution on pupils meeting the listening competencies required at schools and in life (Doyle, 2019; Dehham et al., 2018; Thistle \& McNaughtona, 2015).

Ineffectiveness of Digital Storytelling Strategy for Teaching the Arabic Language on creative thinking skills in levels (flexibility and originality)

The findings may be attributed to the equivalence between the experimental group, which studied the Arabic language by using digital storytelling, and the control group that studied the same subject matter by using the ordinary method; or the procedures used by the teacher who used the digital storytelling strategy are closer to the procedures that were used by the teacher who used the traditional method. It may also be attributed to the fact that the pupils themselves were applying the same method in comprehending the text they listened to in terms of imagining the settings and the characters of the story as in the method used in the group which applied the digital storytelling (Ersoy \& Başer, 2014). Thus, the control group members were not exposed directly to the digital storytelling technique, yet, were indirectly implementing the same style of individual learning and understanding (Al-Fuqaha \& Tobasi, 2015).

The findings may be attributed to the probability that the teacher who taught the experimental group pupils did not cover the subject matter using digital storytelling and lack of commitment to teaching plans.

The Digital Storytelling strategy stimulates students' brainstorming skills through the various activity's teachers can implement along with this strategy. It broadens their imagination and enables them to develop their versions of the story characters, settings, and the endings they desire. Moreover, it gives them the chance to be involved in the listening activity, making them more engaged in the teaching-learning process through the modern strategy that fits their technological competencies as the 21 st-century generation.

\section{Recommendations}

In light of these findings, the following recommendations were presented to future researchers:

- Investigate the effectiveness of using digital storytelling to develop linguistic skills for basic stage pupils and kindergarten children.

- Detecting the effect of using digital storytelling in developing social skills and ethical values of children

- Implementing digital storytelling method and the way to apply it in language teachers training programs

- Detecting the new technologies that can enhance the novelty of the digital storytelling approach to comply with the new technological era's requirements.

- Implementing digital storytelling strategy in teaching Arabic language inside the classrooms

\section{Limitations}

This study was restricted to basic third-grade pupils in private schools in Amman Governorate in Jordan for the academic year 2019/2020. The study is restricted to digital storytelling, which was selected to suit active listening and creative thinking skills.

\section{Acknowledgments}

The author is grateful to the Middle East University, Amman, Jordan, for the financial support granted to cover the publication fee of this research article

\section{References}

Akard, T. F., Dietrich, M. S., Friedman, D. L., Hinds, P. S., Given, B., Wray, S., \& Gilmer, M. J. (2015). Digital storytelling: An innovative legacy-making intervention for children with cancer. Pediatric Blood and Cancer, 62(4), 658-665. https://doi.org/10.1002/pbc.25337

Al-Fuqaha, I. N., \& Tobasi, A. (2015). Creative thinking of university teachers in the age of intellectual capital: is it affected by personality types and traits? Journal on Educational Psychology, 9(2), 8-18. 
https://doi.org/10.26634/jpsy.9.2.3650

Copeland, S., \& de Moor, A. (2018). Community digital storytelling for collective intelligence: Towards a storytelling cycle of trust. AI and Society, 33, 101-111. https://doi.org/10.1007/s00146-017-0744-1

Cunsolo Willox, A., Harper, S. L., \& Edge, V. L. (2012). Storytelling in a digital age: Digital storytelling as an emerging narrative method for preserving and promoting indigenous oral wisdom. Qualitative Research, 13(2), 127-147. https://doi.org/10.1177/1468794112446105

Dehham, S. H., Hasan, A. A. N., \& Raheem, M. D. (2018). The impact of reciprocal listening activities on fifth preparatory students' listening comprehension. Academic Scientific Journal, (38), 1339-1351.

Doyle, A. (2019). Important active listening skills and techniques. The Balance Careers. https://www.thebalancecareers.com/active-listening-skills-with-examples-2059684

Duman, B., \& Göcen, G. (2015). The effect of the digital storytelling method on pre-service teachers' creative writing skills. Anthropologist, 20(1-2), 215-222.

Ellison, T. L., \& Wang, H. (2018). Resisting and redirecting: Agentive practices within an African American parent-child dyad during digital storytelling. Journal of Literacy Research, 50(1), 52-73. https://doi.org/10.1177/1086296X17751172

Ersoy, E., \& Başer, N. (2014). The effects of problem-based learning method in higher education on creative thinking. Procedia - Social and Behavioral Sciences, 116, 3494 - 3498. https://doi.org/10.1016/j.sbspro.2014.01.790

Finch, C. R., \& Crunkilton, J. R. (1998). Curriculum development in vocational and technical education: Planning, content, and implementation (5th ed.). Pearson.

Fleith, D. (2020). Effects of a creativity training program on divergent thinking abilities and self-concept in monolingual and bilingual classrooms. Creativity Research Journal, 14(4), 13-25.

Hamilton, A., Rubin, D., Tarrant, M., \& Gleason, M. (2019). Digital storytelling as a tool for fostering reflection. Frontiers: The Interdisciplinary Journal of Study Abroad, 31, 59-73. https://doi.org/10.36366/frontiers.v31i1.443

Hutchins, S., McDermott, P., Carolan, T., Gronowski, M., Fisher, A., \& DeMay, M. (2013). Interpersonal Skills Summary Report. In United States Army Research Institute for the Behavioral and Social Sciences. https://doi.org/10.1037/e500952014-001

Kardoyo, Nurkhin, A., Muhsin, \& Pramusinto, H. (2020). Problem-based learning strategy: Its impact on students' critical and creative thinking skills. European Journal of Educational Research, 9(3), 1141-1150. https://doi.org/10.12973/eu-jer.9.3.1141

Kawamichi, H., Yoshihara, K., Sasaki, A. T., Sugawara, S. K., Tanabe, H. C., Shinohara, R., Sugisawa, Y., Tokutake, K., Mochizuki, Y., Anme, T., \& Sadato, N. (2015). Perceiving active listening activates the reward system and improves the impression of relevant experiences. Social Neuroscience, 10(1), 16-26. https://doi.org/10.1080/17470919.2014.954732

Kervin, L., \& Mantei, J. (2017). Children creating multimodal stories about a familiar environment. Reading Teacher, 76(6), 721-728. https://doi.org/10.1002/trtr.1556

Kohpeima Jahromi, V., Tabatabaee, S. S., Esmaeili Abdar, Z., \& Rajabi, M. (2016). Active listening: The key of successful communication in hospital managers. Electronic Physician, 8(3), 2123-2128. https://doi.org/10.19082/2123

Kourmousi, N., Amanaki, E., Tzavara, C., \& Koutras, V. (2017). Active listening attitude scale (ALAS): Reliability and validity in a nationwide sample of greek educators. Social Sciences, 6(1), 1-18. https://doi.org/10.3390/socsci6010028

Lisenbee, P. S., \& Ford, C. M. (2018). Engaging students in traditional and digital storytelling to make connections between pedagogy and children's experiences. Early Childhood Education Journal, 46, 129-139. https://doi.org/10.1007/s10643-017-0846-x

McLellan, H. (2007). Digital storytelling in higher education. Journal of Computing in Higher Education, 19, 65-79. https://doi.org/10.1007/BF03033420

Nam, C. W. (2017). The effects of digital storytelling on student achievement, social presence, and attitude in online collaborative learning environments. Interactive Learning Environments, 25(3), 412-427. https://doi.org/10.1080/10494820.2015.1135173

Ng, W., \& Nicholas, H. (2015). iResilience of science pre-service teachers through digital storytelling. Australasian Journal of Educational Technology, 31(6), 1-8. https://doi.org/10.14742/ajet.1699

Patrick, M. D. (2019). The art of digital storytelling. In D. R. Stukus, M. D. Patrick \& K. E. Nuss (Eds.), Social media for 
medical professionals (pp. 83-100). Springer. https://doi.org/10.1007/978-3-030-14439-5_5

Price, D. M., Strodtman, L., Brough, E., Lonn, S., \& Luo, A. (2015). Digital storytelling. Nurse Educator, 40(2), 66-70. https://doi.org/10.1097/NNE.0000000000000094

Robin, B. R. (2008). Digital storytelling: A powerful technology tool for the 21st century classroom. Theory into Practice, 47(3), 220-228. https://doi.org/10.1080/00405840802153916

Simsek, M. R. (2020). Towards emancipatory L2 instruction: exploring significant learning outcomes from collaborative digital storytelling. International Journal of Educational Methodology, 6(3), 555-569. https://doi.org/10.12973/ijem.6.3.555

Tan, M., Lee, S. S., \& Hung, D. W. L. (2014). Digital storytelling and the nature of knowledge. Education and Information Technologies, 19, 623-635. https://doi.org/10.1007/s10639-013-9280-x

Thistle, J. J., \& McNaughtona, D. (2015). Teaching active listening skills to pre-service speech-language pathologists: A first step in supporting collaboration with parents of young children who require AAC. Language, Speech, and Hearing Services in Schools, 46(1), 44-55. https://doi.org/10.1044/2014_LSHSS-14-0001

Toheri, Winarso, W., \& Haqq, A. A. (2020). Where exactly for enhance critical and creative thinking: The use of problem posing or contextual learning. European Journal of Educational Research, 9(2), 877-887. https://doi.org/10.12973/eu-jer.9.2.877

Wechsler, S. M., Saiz, C., Rivas, S. F., Vendramini, C. M. M., Almeida, L. S., Mundim, M. C., \& Franco, A. (2018). Creative and critical thinking: Independent or overlapping components? Thinking Skills and Creativity, 27, 114-122. https://doi.org/10.1016/j.tsc.2017.12.003

Weger, H., Castle Bell, G., Minei, E. M., \& Robinson, M. C. (2014). The relative effectiveness of active listening in initial interactions. International Journal of Listening, 28(1), 13-31. https://doi.org/10.1080/10904018.2013.813234

Wu, J., \& Chen, D. -T. V. (2020). A systematic review of educational digital storytelling. Computers and Education, 147, 10-23. https://doi.org/10.1016/j.compedu.2019.103786 